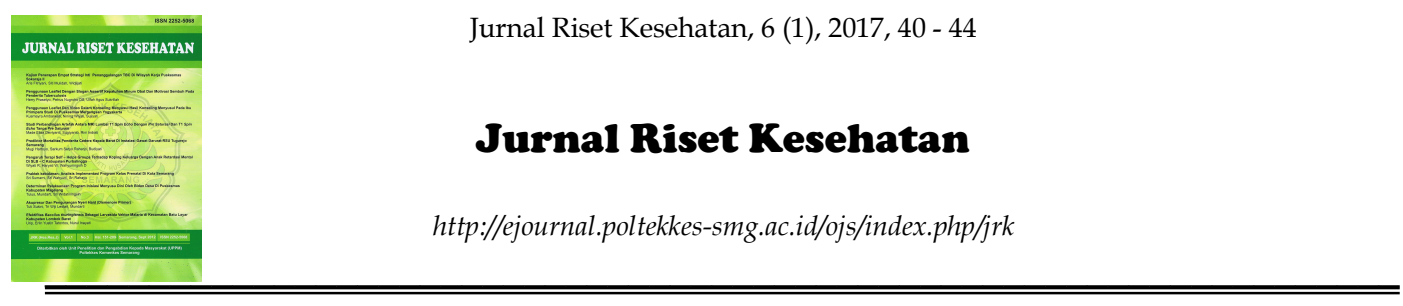

\title{
HUBUNGAN HIGIENE SANITASI DENGAN KEJADIAN INFEKSI Soil Transmitted Helminths PADA PEMULUNG DI TPS JATIBARANG
}

\author{
Lilik Setyowatiningsih*) ; Surati Surati \\ Jurusan Analis Kesehatan ; Poltekkes Kemenkes Semarang \\ Jalan Woltermonginsidi No.115 ; Pedurungan; Semarang
}

\begin{abstract}
Abstrak
Penyakit cacingan masih sering dijumpai di seluruh wilayah Indonesia terutama pada kondisi sanitasi lingkungan yang buruk dan rendahnya higienitas perorangan. Salah satu penyakit cacingan yang masih banyak terjadi pada penduduk di Indonesia disebabkan oleh Soil Transmitted Helminths (STH) yaitu golongan nematode usus yang siklus hidupnya melalui media tanah. Menurut Depkes tahun 2006 prevalensi kecacingan untuk semua umur di Indonesia antara 40\%-60\%. Lokasi dalam penelitian ini yaitu Tempat Pembuangan Sampah (TPS) di Daerah Jatibarang yang merupakan sentral TPS di kota Semarang dengan kondisi sanitasi lingkungan yang kumuh. Hasil penelitian tahun 2005, diketahui sebanyak 47,5 \% pemulung di TPS Jatibarang mengalami kecacingan dengan jenis infeksi tunggal. Tujuan penelitian untuk Mengetahui hubungan higiene sanitasi dengan infeksi Soil Transmitted Helminths pada pemulung di TPS Jatibarang Kota Semarang. Berdasarkan hasil penelitian, sebagian besar pemulung di TPS Jatibarang Kabupaten Semarang sudah menerapkan higiene sanitasi lingkungan dengan baik sehingga kejadian infeksi kecacingan pada pemulung di TPS Jatibarang $100 \%$ negatif.
\end{abstract}

Kata kunci: Higiene sanitasi ; Infeksi Soil Transmitted Helminths

\begin{abstract}
[SANITATION HYGIENE RELATIONSHIP WITH INFECTION SOIL TRANSMITTED HELMINTHS OF SCAVENGERS IN TPS JATIBARANG] Worming often be found in all parts of Indonesia, especially in conditions of poor sanitation and lack of hygiene individually. A deworming still causes much of the population in Indonesia by the Soil Transmitted Helminths (STH) is a group of intestinal nematode life cycle through the soil media. According to the Depkes, the prevalence of worm infection in 2006 for all ages in Indonesia between 40\%-60\%. The location of this research waste (TPS) in the Jatibarang region which is a central polling station in the city of Semarang with sanitary conditions of slums. The results of the study in 2005, known as much as $47.5 \%$ of scavengers in TPS Jatibarang experienced some worm infection and type of infection. Knowing the purpose of the research for sanitary hygiene related to infection Soil Transmitted Helminths TPS Jatibarang scavengers in the city of Semarang. Based on the research results, mainly scavengers TPS Jatibarang Semarang District has sanitation hygienic environment so well that the incidence of worm infection on a scavenger TPS Jatibarang 100\% negative implemented.
\end{abstract}

Keywords: Sanitation hygiene ; infection Soil Transmitted Helminths

\section{Pendahuluan}

Penyakit kecacingan atau biasa disebut cacingan kurang mendapat perhatian yang cukup oleh sebagian besar masyarakat indonesia. Salah satu jenis penyakit ini adalah penyakit kecacingan yang disebabkan oleh

*) Lilik Setyowatiningsih

E-mail: liliksetyowati70@gmail.com infeksi cacing kelompok Soil Transmitted Helminths (STH) (Dachi, 2005). Soil Transmitted Helminths adalah nematoda usus yang perkembangan embrionya pada tanah. Ada 3 jenis cacing STH di Indonesia yang sering menginfeksi manusia, yaitu Cacing Gelang (Ascaris lumbricoides) ,Cacing Cambuk (Trichuris trichiura) dan Cacing Tambang (Necator americanus dan Ancylostoma duodenale) (Arsanti, 2011). Infestasi cacing usus masih merupakan 
masalah kesehatan masyarakat yag dilaporkan di negara-negara berkembang seperti Indonesia, dimana faktor higiene dan sanitasi lingkungan merupakan faktor penting dari transmisi penyakit ini.

Hasil penelitian tahun 2005, diketahui sebanyak $47,5 \%$ pemulung di TPS Jatibarang mengalami kecacingan dengan jenis infeksi tunggal dan tidak ada infeksi ganda. Tahun 2010 hasil penelitian pada pemulung di Tempat Pembuangan Akhir Kalongan ungaran Kabupaten Semarang menunjukkan prevalensi kecacingan sebesar 21,4\%. Hasil survei Departemen Kesehatan Republik Indonesia di beberapa provinsi di Indonesia menunjukkan prevalensi kecacingan untuk semua umur di Indonesia berkisar antara 40\%-60\%. Tingginya prevalensi ini disebabkan oleh iklim tropis dan kelembaban udara tinggi di Indonesia, yang merupakan lingkungan yang baik untuk perkembangan cacing, serta kondisi higiene dan sanitasi yang buruk (Depkes RI, 2006).

Sampah sebagai hasil sampingan dari berbagai aktivitas dalam kehidupan manusia maupun sebagai hasil dari proses alamiah, seringkali menimbulkan permasalahan diperkotaan. Semakin berkembang suatu kota akibat pertambahan jumlah penduduk serta peningkatan aktivitas hidupnya menyebabkan masalah yang ditimbulkan oleh sampah semakin besar dan kompleks (Slamet, 2004). Kondisi tanah yang lembab dengan bertumpuknya banyak sampah merupakan habitat yang tepat untuk nematoda hidup dan berkembang biak. Tekstur tanah yang sangat bervariasi yang terdiri dari tanah pasir, debu dan tanah liat sangat memungkinkan hidup dan berkembang biak telur-telur cacing Soil Transmitted Helminths (STH) hingga menjadi cacing yang infektif menularkan penyakit kecacingan.

Higiene adalah ilmu tentang kesehatan dan berbagai usaha untuk mempertahankan dan memperbaiki kesehatan. Higiene perorangan bisa tercapai bila seseorang mengetahui pentingnya menjaga kesehatan dan kebersihan diri, karena pada dasarnya higiene adalah mengembangkan kebiasaan yang baik untuk kesehatan (Hasyimi, 2001). Sanitasi adalah usaha kesehatan masyarakat yang menitik beratkan pada pengawasan terhadap berbagai faktor lingkungan yang mempengaruhi derajat kesehatan manusia. Jadi lebih baik mengutamakan usaha pencegahan terhadap berbagai faktor lingkungan sehingga dapat menghindari munculnya berbagai penyakit (Hasyimi, 2001).

Tempat Pembuangan Sampah (TPS) Daerah Jatibarang merupakan pusat tempat pembuangan sampah di kota Semarang. Sampah berasal dari limbah rumah tangga maupun industri di kota Semarang. Sampah yang masuk ke TPS dibedakan menjadi dua jenis yaitu sampah organik dan sampah anorganik. Sampah anorganik meliputi sampah plastik, besi dan kaca yang bisa didaur ulang kembali. Adanya sampah-sampah anorganik di TPS ini yang membuat para pemulung tertarik untuk mengais rejeki dengan memulung sampah yang bisa didaur ulang dan kemudian dijual kepengepul barang rosok.

Pekerjaan pemulung sampah dilakukan dari pagi sampai sore hari mereka pun kerap kali melakukan aktifitas ditempat dimana mereka bekerja, seperti makan, minum, buang air kecil, dan buang air besar, tanpa memperhatikan kesehatan dan kebersihan yang baik. Higiene dan sanitasi mereka yang kurang baik, seperti tidak menggunakan alas kali selama bekerja, tidak mencuci tangan sebelum makan, buang air kecil dan buang air besar sembarangan, akan mengundang berbagai penyakit, salah satunya yaitu penyakit kecacingan, khususnya infeksi cacing dari golongan Soil transmitted helminths. Bahkan, di musim hujan pun mereka tetap memulung sampah, tanpa mempedulikan kondisi tanah yang licin dan lembab, sehingga memungkinkan untuk telur cacing dari STH bertahan hidup.

\section{Metode}

Rancangan penelitian ini adalah observasional dengan kriteria penelitian analitik dengan pendekatan cross sectional yang bertujuan untuk mengetahui gambaran infeksi Soil Transmitted Helminths pada pemulung di TPS daerah Jatibarang kota Semarang dan kuesioner yang bersifat observasi untuk menggambarkan higiene sanitasi. Data penelitian ini diperoleh dari pemeriksaan laboratorium pada tinja untuk mengetahui infeksi Soil Transmitted Helminths dan selanjutnya dihubungkan dengan data kuesioner kemudian disajikan dalam bentuk tabel dan dianalisa secara analitik.

Data yang di kumpulkan dalam penelitian ini meliputi data primer dan data sekunder yang dikumpulkan langsung dari subjek penelitian oleh peneliti yaitu : Data Primer yaitu data infeksi telur cacing STH yang diperoleh dari 
pemeriksaan tinja responden dengan metode langsung. Data Sekunder yaitu data Higiene sanitasi pada pemulung di TPS daerah Jatibarang kota Semarang yang diperoleh melalui kuesioner. Alat yang digunakan dalam penelitian yaitu mikroskop, objekglass, deckglass, pipet tetes, lidi dan pot feses. Bahan yang digunakan adalah eosin $2 \%$ (Indo Reagen) dan feses. Prosedur pemeriksaan dengan menggunakan metode langsung yaitu : Menyediakan objek glass yang sudah dibersihkan kapas alkohol.; Menetesi objek glass dengan reagen eosin $2 \%$ sebanyak 1 tetes.; Mengambil sedikit feses dan mencampur hingga homogen dengan menggunakan lidi.; Menutup objek glass dengan dekglass dan melakukan pemeriksaan dibawah mikroskop (Axiom Germany) dengan perbesaran 10-40x.

\section{Hasil dan Pembahasan}

Berdasarkan pemeriksaan feses pada pemulung di Tempat Pembuangan Sampah Jatibarang Kabupaten Semarang, yang berjumlah 39 orang, pada bulan AgustusSeptember 2016 memberikan hasil yang dapat dilihat dalam tabel sebagai berikut :

Tabel 1. Prevalensi Infeksi Telur Cacing Soil Transmitted Helmint (STH) pada pemulung di TPS Jatibarang berdasarkan derajat higiene sanitasi para pemulung.

\begin{tabular}{|c|c|c|c|c|c|c|}
\hline \multirow{2}{*}{$\begin{array}{l}\text { HIGIENE } \\
\text { SANITASI }\end{array}$} & \multicolumn{4}{|c|}{ POSITIF } & \multirow[b]{2}{*}{ NEGATIF } & \multirow[b]{2}{*}{ JUMLAH } \\
\hline & $\begin{array}{c}\text { Ascaris } \\
\text { lumbricoides }\end{array}$ & $\begin{array}{l}\text { Trichuris } \\
\text { trichiura }\end{array}$ & $\begin{array}{c}\text { Cacing } \\
\text { Tambang }\end{array}$ & JUMLAH & & \\
\hline BAIK & $(0 \%)$ & $(0 \%)$ & $\dot{-}$ & $\dot{-}$ & $\begin{array}{c}39 \\
(100 \%)\end{array}$ & $\begin{array}{c}39 \\
(100 \%) \\
\end{array}$ \\
\hline $\begin{array}{l}\text { KURANG } \\
\text { BAIK }\end{array}$ & $(0 \%)$ & $\dot{-}$ & $(0 \overline{\%})$ & $(0 \%)$ & $\begin{array}{c}39 \\
(100 \%)\end{array}$ & $\begin{array}{c}39 \\
(100 \%)\end{array}$ \\
\hline \multicolumn{4}{|c|}{ TOTAL } & $\dot{-}$ & $\begin{array}{c}39 \\
(100 \%)\end{array}$ & $\begin{array}{c}39 \\
(100 \%)\end{array}$ \\
\hline
\end{tabular}

Berdasarkan Tabel 1, dapat diketahui bahwa semua pemulung di TPS Jatibarang yang berjumlah 39 orang $(100 \%)$ mempunyai derajat hygiene sanitasi baik. Apabila dilihat dari infeksi telur cacing STH, diketahui bahwa tidak ada pemulung yang terinfeksi telur cacing STH.

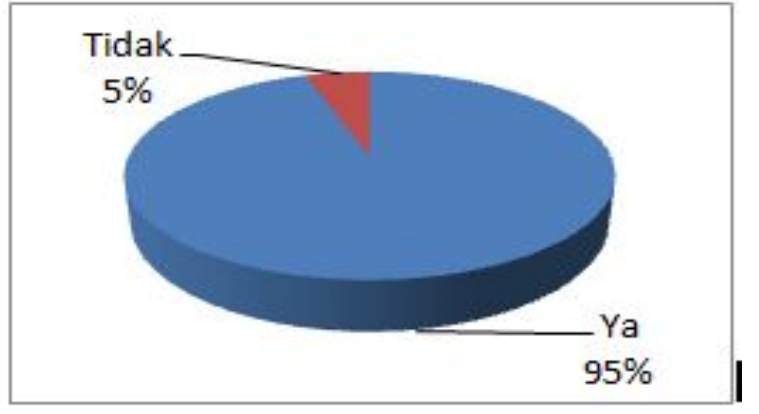

Gambar 1. Proporsi Responden Berdasarkan Kebiasaan Mencuci Tangan Dengan Air Bersih Dan Sabun Sebelum Makan

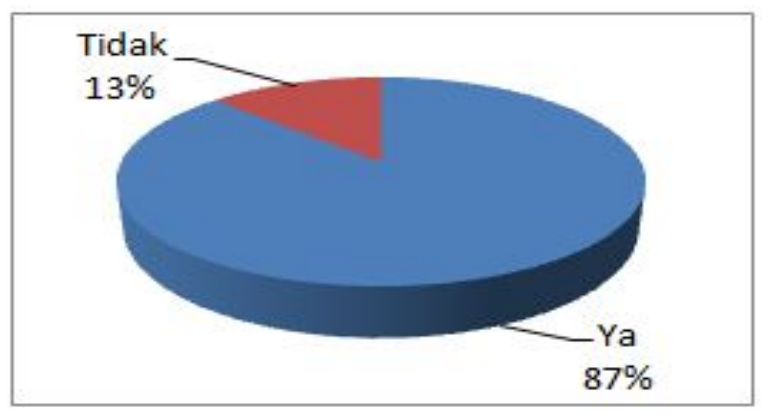

Gambar 2. Proporsi Responden Berdasarkan Kebiasaan Memotong Kuku Dan Membersihkan Kuku Seminggu Sekali

Pada gambar 2, dapat diketahui bahwa sebagian besar para pemulung di TPS Jatibrang kabupaten Semarang mempunyai kebiasaan Memotong kuku dan membersihkan kuku seminggu sekali dengan persentase sebesar $87 \%$. Sedangkan yang tidak mempunyai kebiasaan tersebut mempunyai persentase lebih sedikit, yaitu sebesar $13 \%$.

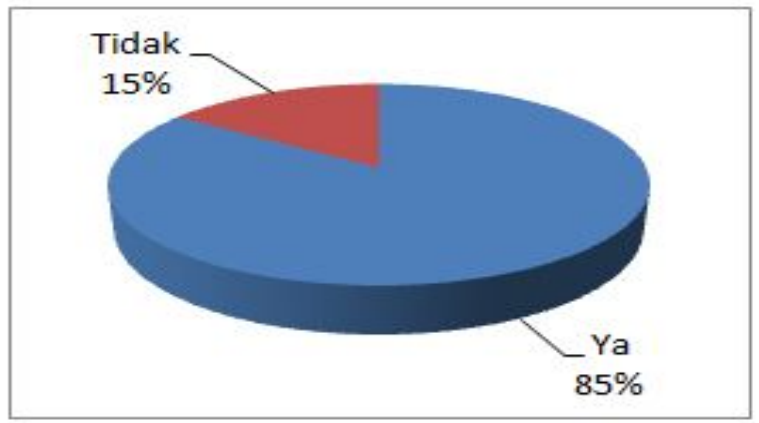

Gambar 3. Proporsi Responden Berdasarkan Terpenuhinya Sumber Air Bersih Di Tempat Kerja

Pada gambar 3, dapat diketahui bahwa sebagian besar para pemulung di TPS Jatibarang kabupaten Semarang sadar akan adanya ketersediaan sumber air bersih di tempat kerja dengan persentase sebesar $85 \%$. Sedangkan 
yang belum menyadari pentingnya sumber air bersih di tempat kerja mempunyai persentase lebih sedikit, yaitu sebesar 15\%.

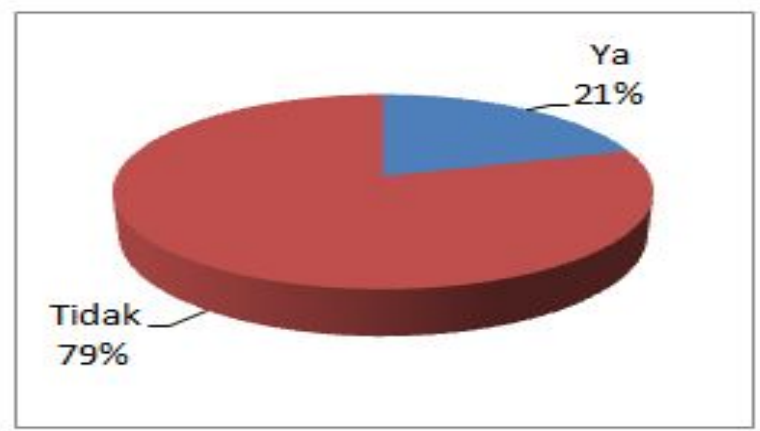

Gambar 4. Proporsi Responden Berdasarkan Kebiasaan Buang Air Besar Di Lingkungan Sekitar Tempat Kerja

Pada gambar 4, dapat diketahui bahwa sebagian kecil para pemulung di TPS Jatibarang kabupaten Semarang mempunyai kebiasaan buang air besar di lingkungan sekitar tempat kerja dengan persentase sebesar $21 \%$. Sedangkan yang tidak mempunyai kebiasaan Buang air besar di lingkungan sekitar tempat kerja dengan persentase yaitu $79 \%$

Berdasarkan hasil penelitian pada pemulung di Tempat Pembuangan Sampah (TPS) Jatibarang Kabupaten Semarang dengan jumlah 39 orang, didapatkan hasil bahwa tidak ada pemulung yang terinfeksi cacing Soil Transmitted Helminth (STH), dan untuk kategori higiene sanitasi, dari 39 sampel dapat diketahui bahwa semua pemulung di Tempat Pembuangan Sampah (TPS) di Jatibarang berkategori higiene sanitasi baik.

Berdasarkan hasil rekapitulasi derajat higiene sanitasi para pemulung di TPS Jatibarang, menunjukkan bahwa kebiasaan memakai alas kaki saat berada di tempat kerja sudah baik, yaitu semua pemulung $(100 \%)$ telah memakai alas kaki saat bekerja baik itu berupa sandal maupun sepatu, (87\%) sudah memotong kuku dan membersihkan kuku seminggu sekali, $(85 \%)$ menyadari adanya sumber air bersih di tempat kerja, (79\%) tidak buang air besar di lingkungan sekitar tempat kerja dan (100\%) dari seluruh responden telah mempunyai jamban.

Berdasarkan data hasil rekapitulasi kuesioner yang diterima diketahui bahwa sebagian besar pemulung di TPS Jatibarang Kabupaten Semarang sudah mampu menerapkan higiene diri dan sanitasi lingkungan, serta mereka menyadari bahwa pekerjaan yang dilakukan oleh mereka sangat beresiko terhadap penyakit, khususnya penyakit kecacingan oleh telur STH, Pencemaran telur cacing tersebut terjadi karena pencemaran tanah oleh tinja, hal ini memudahkan transmisi telur dari tanah kepada manusia melalui tangan yang tercemar oleh telur cacing parasit, kemudian masuk ke mulut bersama makanan.

\section{Simpulan dan Saran}

Berdasarkan kategori higiene sanitasi, dari 39 responden dapat diketahui bahwa semua pemulung di Tempat Pembuangan Sampah (TPS) di Jatibarang berkategori higiene sanitasi baik. Berdasarkan hasil pemeriksaan feses, dari 39 sampel $(100 \%)$ Tidak ditemukan adanya infeksi Soil Transmitted Helminths (STH) pada pemulung di TPS Jatibarang kota Semarang. Tidak ada hubungan antara hygiene sanitasi terhadap infeksi Soil Transmitted Helmints (STH) pada pemulung di TPS Jatibarang kota Semarang

Bagi peneliti selanjutnya diharapkan melakukan penelitian atau pengabdian masyarakat berkesinambungan dengan melakukan pemeriksaan telur cacing STH dengan metode lain dan melakukan pengulangan pemeriksaan agar hasilnya lebih akurat. Bagi Masyarakat terutama pemulung di TPS Jatibarang Kabupaten Semarang diharapkan meningkatkan Perilaku Hidup Bersih dan Sehat agar terhindar dari penyakit kecacingan. Bagi Dosen dan Mahasiswa diharapkan dapat melakukan penelitian sejenis di TPS Jatibarang Kabupaten Semarang akan tetapi dengan sasaran atau pemeriksaan yang berbeda.

\section{Ucapan Terima Kasih}

Ucapan banyak terima kasih disampaikan atas kesempatan yang diberikan untuk mendapatkan Dana Risbinakes DIPA Politeknik Kesehatan Kemenkes Semarang, sehingga penelitian ini dapat terselesaikan.

\section{Daftar Pustaka}

Arsanti dkk. (2011) Infeksi Cacing (Penyakit Kecacingan), BBTKL PPM. Yogyakarta: Jurnal Media Informasi Kegiatan, Volume 9.

Dachi, R.A.(2005) Hubungan Perilaku Anak Sekolah Dasar Terhadap Infeksi Cacing Perut Di Kecamatan Palipi Kabupaten Samosir Tahun 2005. Jurnal Mutiara Kesehatan Indonesia.vol.1.(2), Hal 1-7 
Dahlan, Muhamad Sopiyudin. (2011). Statistik untuk Kedokteran dan Kesehatan: Deskriptif, Bivariat, dan Multivariat, Dilengkapi Aplikasi dengan menggunakan SPSS Edisi 5. Jakarta: Salemba Medika.

Depkes RI. (2006). Pedoman PengendalianKecacingan. Diunduh dari: http://www.depkes.go.id

Dinas Kebersihan dan Pertamanan Kota Semarang. Diunduh tanggal 20 Oktober 2016 dari http://dkp.semarangkota.go.id/index.p $\mathrm{hp} /$ content/tpa_uptd

Inge Sutanto dkk. (2008). Parasitologi Kedokteran. Staf Pengajar Departemen Parasitologi FKUI : Jakarta.

Garcia, LS. (2003). Diagnostik Parasitologi Kedokteran. Penerbit Buku Kedokteran: ECG.

Ginting. S. A, (2003). Hubungan Antara Status Social Ekonomi Dengan Kejadian Kecacingan Pada Anak Sekolah Dasar. Digitized by USU digital library.

Hasyimi. M.(2001). Kaitan Pengetahuan dan Kebiasaan dengan Infeksi kecacingan. Media Litbang Kesehatan. Volume XI Nomer 3 : Jakarta.

Hadidjaja, Pinardi. (2001) Penuntun Laboratorium Parasitologi Kedokteran. Jakarta: FKUI.

Irianto, Koes. (2013). Parasitoloi Medis ( Medical Parasitology). Penerbit Buku Alfabeta, cv : Bandung.

Jangkung. S. O. (2002). Parasitologi Medik 1 Helmintologi. Penerbit Buku Kedokteran EGC : Jakarta.

Notoatmodjo, Soekidjo. (2007). Kesehatan Masyarakat Ilmu \& Seni. Jakarta: Rineka Cipta
Puspitasari , Fitri. Skripsi.(2005). Hubungan Kecacingan Dengan Status Gizi Pada Pemulung Di Tempat Pembuangan Akhir (TPA) Jatibarang Kecamatan Mijen Kota Semarang. Universitas Diponegoro.

Rianda. (2014). Pengetahuan dan Tindakan Personal Hygiene Pemunlung Sampah, Jurnal Kesehatan, Volume V, Nomor 2,Oktober 2014, hlm 162-166

Safar R. (2010). Parasitologi Kedokteran: Protozoologi, Entomologi, dan Helmintologi. Y rama Widya: Bandung.

Simanjuntak, Lisnawaty. (2013). Sanitasi, Hygiene, dan Keselamatan Kerja. Direktorat Pembinaan SMK. Diunduh pada tanggal 02 Desember 2014 dari http:// belajar.ditpsmk.net/wpcontent/uploads/2014/09/SANITASIHYGIENE-DAN-KESELAMATANKERJA-X.pdf.

Slamet, J.S.(2004) Kesehatan Lingkungan. Gadjah Mada University Press. Yogyakarta

Sumanto, Didik. Tesis. (2010). Faktor resiko infeksi cacing tambang pada anak sekolah dasar. Prodi Magister Epidemiologi Universitas Diponegoro. Diunduh pada tanggal 12 November 2014 dari http://eprints.undip.ac.id/23985/1/1/ DIDIK SUMANTO.pdf

Surahma, A.M.,Damaiyanti, M. (2013) Hubungan Antara Kebiasaan Penggunaan Alat Pelindung Diri dan Personal Hygiene Dengan Kejadian Infeksi Kecacingan Pada Petugas Sampah di Kota Yogyakarta. Jurnal Ekologi Kesehatan Vol. 12 No 2, Juni 2013 : $161-170$ 